\title{
A study on landuse and landcover classification using microwave data in Joida taluk of Uttara Kannada district, Karnataka
}

\author{
Arjun. G. Koppad* \\ Department of Natural Resource Management, College of Forestry, Sirsi (Karnataka), \\ India \\ Syeda Sarfin \\ Department of Natural Resource Management, College of Forestry, Sirsi (Karnataka), \\ India
}

\section{Anup Kumar Das}

Space Application centre, Ahmedabad (Gujarat), India

*Corresponding author. E-mail: koppadag2007@rediffmail.com

\begin{abstract}
The study has been conducted for land use and land cover classification by using SAR data. The study included examining of ALOS 2 PALSAR L- band quad pol $(\mathrm{HH}, \mathrm{HV}, \mathrm{VH}$ and VV) SAR data for LULC classification. The SAR data was pre-processed first which included multilook, radiometric calibration, geometric correction, speckle filtering, SAR Polarimetry and decomposition. For land use land cover classification of ALOS-2PALSAR data sets, the supervised Random forest classifier was used. Training samples were selected with the help of ground truth data. The area was classified under 7 different classes such as dense forest, moderate dense forest, scrub/sparse forest, plantation, agriculture, water body, and settlements. Among them the highest area was covered by dense forest (108647ha) followed by horticulture plantation (57822 ha) and scrub/Sparse forest (49238 ha) and lowest area was covered by moderate dense forest (11589 ha). Accuracy assessment was performed after classification. The overall accuracy of SAR data was $80.36 \%$ and Kappa Coefficient was 0.76 . Based on SAR backscatter reflectance such as single, double, and volumetric scattering mechanism different land use classes were identified.
\end{abstract}

Keywords: Decomposition, Forest, LULC, Microwave, Polarization, Polarimetry

\section{INTRODUCTION}

Remote sensing is an art of acquiring data/ information about an object, process or a place without being in direct contact with the sensor (Campbell et al. 2011; James B et at.2011). Remote sensing provides real time data. It has capabilities to address various global applications including agriculture, forestry, meteorology, geology and environmental studies. The remote sensing provides a platform to analyze large area within short time period (Roy et al.2017; Behera et al. 2017).

Microwave remote sensing uses microwave region of electromagnetic spectrum. The application of microwaves in remote sensing is motivated because of its cloud penetrating and all weather imaging properties (Pampaloni et al. 2004; Paolo et al. 2004). It provides unique capability towards monitoring earth. RADAR or radio detection and ranging is an active microwave sensor. It is the main tool used for natural resource mapping and

\section{Article Info}

https://doi.org/

10.31018/jans.v12i1.2209

Received: December 16, 2019

Revised: January 24, 2020

Accepted: February 2, 2020

\section{How to Cite}

Koppad, A.G. et al. (2020). A Study on Landuse and Landcover Classification using Microwave data in Joida Taluk of Uttara Kannada district, Karnataka. Journal of Applied and Natural Science, 12 (1): $9-12$ https://doi.org/ 10.31018/jans.v12i1.2209 
Garg, et al., 2008). Traditional methods of acquiring data of large area are not always possible and it is time consuming. Remote sensing has become very popular subject in understanding and gathering information about earth and processes. Keeping these points in view the experiment was planned to map the Land use Land cover classes using SAR data.

\section{MATERIALS AND METHODS}

The study area falls between $14^{0} 54^{\prime} 13^{\prime \prime} \mathrm{N}$ to $15^{\circ}$ $31^{\prime} 59^{\prime \prime} \mathrm{N}$ latitude and $74^{\circ} 08^{\prime} 11^{\prime \prime} \mathrm{E}$ to $74^{\circ} 31^{\prime} 10^{\prime \prime} \mathrm{E}$ longitude. This is part of Joida Taluk in Uttar Kannada (UK) district, Karnataka, India. It is tropical evergreen forest which is covered mainly with dense forest. It has diverse land cover types such as plantation, agriculture, forest, settlements and water body. The location map is shown in Fig1.

The study was carried in Joida Taluk of Uattar Kannada district, Karnataka. The data used for the study was ALOS 2 PALSAR, L band SAR data. It had range resolution of $5.1 \mathrm{~m}$ and azimuth resolution of $4.3 \mathrm{~m}$, quad pol data with $\mathrm{HH}, \mathrm{HV}$, $\mathrm{VH}$ and VV polarization. The ALOS 2 PALSAR data is procured from NRSC Hyderabad.

The SAR data contained I, q and intensity bands. These bands were used to create RGB image. The first step towards pre-processing of SAR data involves multilooking to generate square pixel (Dini Das, 2018). The data was radiometrically calibrated. The objective of calibration was to provide an imagery in which the pixel values can be directly related to the radar backscatter. Calibrated SAR images are essential for quantitative use of SAR data. The quad pol data was used to generate Coherency matrix T3. This matrix was preferred because its elements had a physical interpretation (Volume scattering, double bounce scattering, and surface scattering) (Dos Santos, et al. 2009). Further speckle filter was applied to generated matrix by using refined lee $(5 \times 5)$. This process removes speckle noises. The image may contain topographical variations of scene and tilt of satellite sensor. This error can be removed by geometric correction. The data was geometrically corrected which included orientation angle correction and terrain correction. Terrain corrections was done by using range doppler terrain correction which is intended to remove the distortions so that the geometric representation of the image will be as close as possible to real world. The SAR Polarimetry was carried out. Snap software was used to pre-process SAR data.

The decomposition model used for this study was Freeman Durden decomposition. This decomposition models the covariance matrix as the contribution of three scattering mechanism. They are volume scattering, double bounce scattering and surface scattering. The components of these three mechanisms were employed to generate a RGB image under freeman-Durden decomposition in which red indicated double bounce; green indicated volumetric and blue indicated the surface scattering which was used for classification.

The supervised classification is performed by using random forest classifier. The first step towards classification is generation of vector data container of different classes. The different classes were identified based on their scattering, colour and texture. supervised classification is a training based methodology that classifies similar image pixel values into training samples for a determined number of classes (Zakeri et al., 2017; Homa et al., 2017). The supervised classification is conducted by using random forest classifier algorithm. Random forest is a classification and regression tree technique invented by Breiman. It randomly collects the samples of data and variables to generate a large group or forest or classification and regression trees. The area is classified into seven different classes such dense forest, moderate dense forest, scrub/sparse forest, plantation, agriculture, water body, and settlements. The accuracy assessment after the classification is shown in confusion matrix. There are many steps involved in classification of ALOS 2 PALSAR. The generalized flow chart of the methodology is given in Fig. 2.

\section{RESULTS}

The Freeman Durden decomposition allowes to analyse and identify the different feature based on there scattering mechanism. The accuracy results of Freeman Durden decomposition classification was $80.36 \%$ and kappa coefficent was 0.76 . The confusion matrix of the results were produced to show the classified and referenced pixles. The total area is classified under 7 different classes. The area classification is shown in Table 1.

The present study observed that the total classified area of dense forest was 108647 ha, moderate dense forest was 11589 ha, scrub/sparse forest was 49238 ha, horticulture plantation was 57822 ha agriculture was 16061 ha, settlements was 31251 ha and water body was 12393 ha. The blue patch in supervised classified image was water body (Supa reservoir). The river chanels were also identified correctly. The water acted as plane surface which undergoes surface reflectance. The red patches in the image indicated settelemnts and small villages. The settelments mainly underwent double bounce scattering. The combination of dark green and sea greean colour in the image indicated dense forest and moderate dense forest respectively. The plantation is represented by green colour. The yellow colure in the image indicated agriculture. SAR polarimetry is always said useful for forest mapping because of its penetreting properties into dense canopy of trees. The freeman durden decomposition, classi- 
fied image is shown in Fig. 3.

\section{DISCUSSION}

The study has been conducted for LULC classification using ALOS 2 PALSAR data. The Freeman -Durden decomposition models the covariance matrix as the contribution of three scattering mechanisms, (i) Volume scattering where a canopy scatterer is modelled as a set of randomly oriented dipoles, (ii) Double-bounce scattering modelled by a dihedral corner reflector and (iii) Surface or single-bounce scattering modelled by a first-order Bragg surface scatterer (Das, et al. 2018). The scattering model is used to describe the polarimetric backscatter from the natural scattrers. In present study, the supervised classification is ended up with accuracy assessment. The study done by Anthony Freeman and Stephen L.
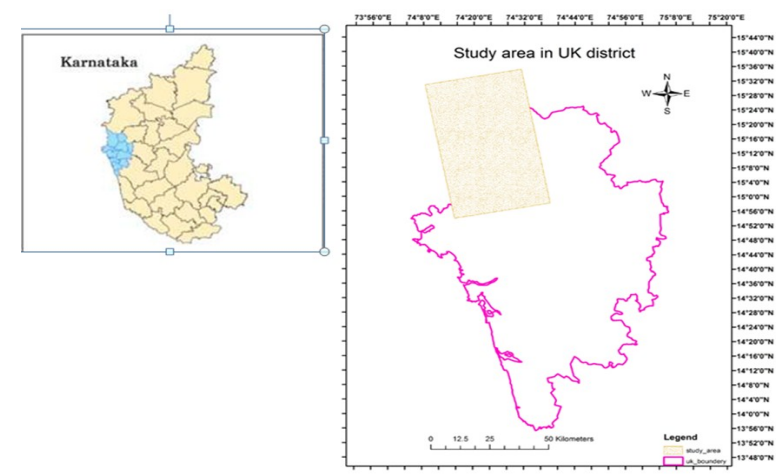

Fig. 1. Study area in Uttara Kannada district of Karnataka.

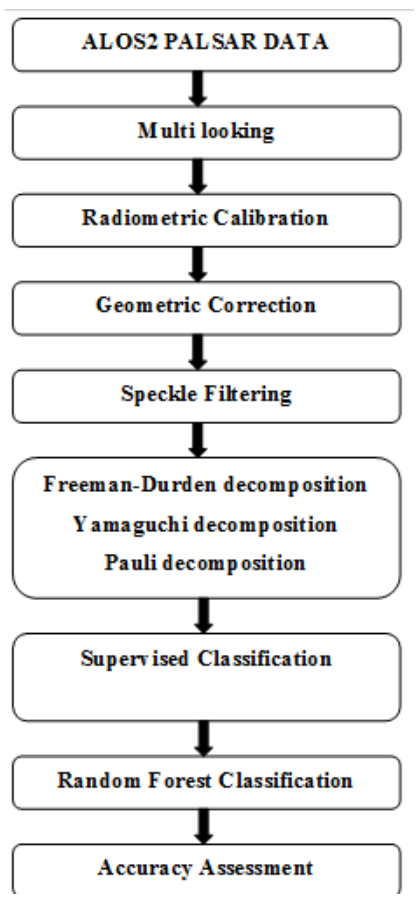

Fig. 2. Flowchart of supervised classification process of ALOS 2 PALSAR.
Durden (1998) also showed the similar results indicating that the three-component scattering mechanism model may prove useful in providing features for distinguishing between different landuse types. The overall accuracy for SAR imagery is $80.36 \%$ and kappa coefficient value is 0.76 . The confusion matrix included the producers and users accuracy. The diagonal elements in the confusion matrix showed the correctly classified pixels in each class. Accuracy assessment after image classification is important to quantitatively assess how effectively the pixels were sampled into the correct land cover class. The totals of 3053 training points were created to classify the study area. The user's accuracy ranged from $66.50 \%$ to $95.75 \%$ and the producer's accuracy ranged from $72.12 \%$ to $92.04 \%$. These wide ranges of accuracy indicated that the misclassification of pixels between different clas-

Table 1. Area showing land use land cover classification of Joida Taluk in Uttar Kannada District.

\begin{tabular}{lll}
$\begin{array}{lll}\text { SI. } \\
\text { No. }\end{array}$ & LULC Classes & \multicolumn{1}{c}{$\begin{array}{c}\text { SAR data } \\
\text { L Band }\end{array}$} \\
\cline { 3 - 3 } & & Total Area(ha) \\
\hline 1. & Dense Forest & 108647 \\
2. & Moderate Dense Forest & 11589 \\
3. & scrub/Sparse Forest & 49238 \\
4. & Horticulture Plantation & 57822 \\
5. & Agriculture & 16061 \\
6. & Settlements & 31251 \\
7. & Water body & 12393 \\
& Total area & $2,87,000$ \\
\hline
\end{tabular}

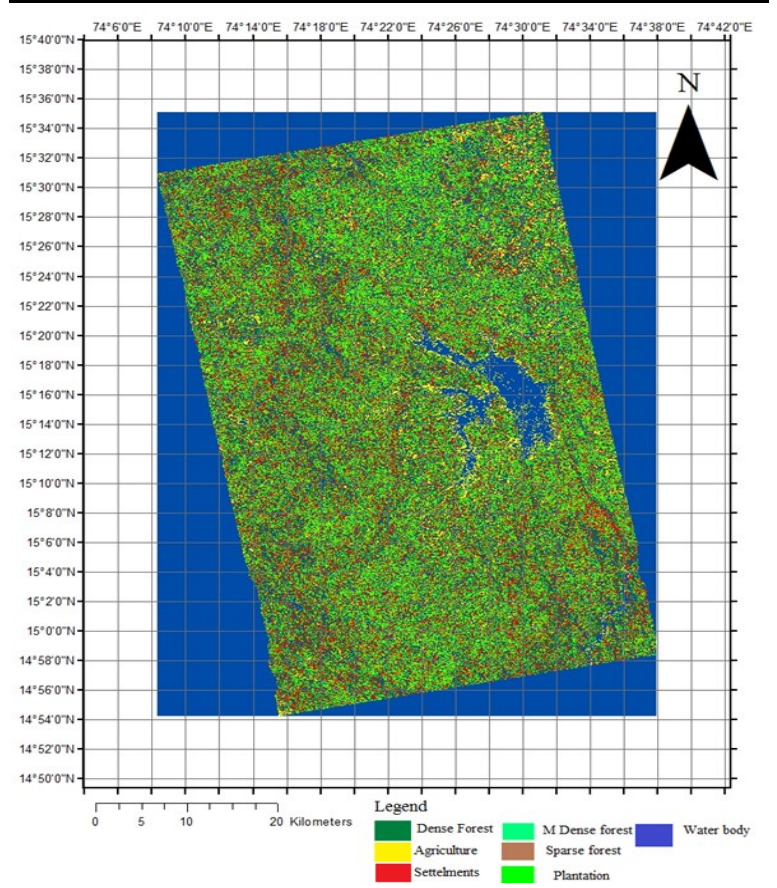

Fig. 3. Freeman dureden supervised classification of Joida Taluk in Uttar Kannda District. 
Table 2. Confusion matrix of SAR data.

\begin{tabular}{lllllllllll}
\hline Classes & $\mathbf{1}$ & $\mathbf{2}$ & $\mathbf{3}$ & $\mathbf{4}$ & $\mathbf{5}$ & $\mathbf{6}$ & $\mathbf{7}$ & Total & $\begin{array}{l}\text { User } \\
\text { accuracy }\end{array}$ & $\begin{array}{l}\text { Producers } \\
\text { accuracy }\end{array}$ \\
\hline Water body(1) & 414 & 0 & 36 & 0 & 0 & 0 & 0 & 450 & $92 \%$ & $81.65 \%$ \\
Settlement (2) & 68 & 266 & 47 & 0 & 0 & 19 & 0 & 400 & $66.50 \%$ & $92.04 \%$ \\
Agriculture(3) & 25 & 23 & 280 & 0 & 0 & 72 & 0 & 400 & $70.00 \%$ & $73.49 \%$ \\
Plantation(4) & 0 & 0 & 0 & 305 & 60 & 0 & 15 & 380 & $76.25 \%$ & $77.80 \%$ \\
Dense forest(5) & 0 & 0 & 0 & 87 & 470 & 0 & 23 & 580 & $81.03 \%$ & $83.48 \%$ \\
Spares/open forest(6) & 0 & 0 & 18 & 0 & 0 & 383 & 19 & 420 & $95.75 \%$ & $72.12 \%$ \\
Mod.Dense Forest(7) & 0 & 0 & 0 & 0 & 33 & 57 & 333 & 423 & $78.72 \%$ & $84.61 \%$ \\
Total & 507 & 289 & 381 & 392 & 563 & 531 & 390 & 3053 & & \\
\hline
\end{tabular}

ses took place. The user's accuracy showed the wide range of accuracy because many training points were included in a class while they belong to another class. The highest user's accuracy was obtained in scrub/sparse forest and the lowest was in settlements. The highest producer's accuracy was obtained in settlements and lowest was in scrub/sparse forest. The misclassification of pixels occurred between the classes such as water body and settlements, plantation and dense forest, and open/sparse forest and moderate dense forest.

Polarimetric SAR data can distinguish forest from other land covers based on their colour and texture. Plantation can be identified by its texture, which is smoother texture than dense forest in present study; the total study area is classified into 7 different classes as shown in table 2 . Among the different LULC classes dense forest covered highest area (108647 ha) followed by horticulture plantation (57822 ha). This showed that SAR data is useful in classifying the types of forest, such as dense forest, moderate dense forest, sparse forest and scrub forest.

\section{Conclusion}

The different scattering mechanism of SAR by different features was used to identify different land use systems. The study area was classified as 7 different land use land cover classes. The classes were grouped under 3 scattering mechanism. The three classes are classified as dense forest, moderate dense forest, and plantation under volume scattering. Settlements, agriculture and scrub/sparse forest are classified under double bounce scattering. The surface scattering was considered to classify water body. The study showed that $L$ band SAR data helped in forest classification. The Freeman- Durden decomposition model allowed classifying features based on their scattering mechanism. The random forest classifier was the most suitable algorithm for land cover classification. This study helps in understanding scenario of different land uses, which helps in protecting and conservation of forest.

\section{REFERENCES}

1. Abdikan, Saygin, Fusun Balik Sanli, M. Ustuner, and Fabiana Calò. (2016).Land cover mapping using sentinel-1 SAR data. The International Archives of Photogrammetry, Remote Sensing and Spatial Information Sciences 41: 757, doi: 10.5194/isprsarchivesXLI-B7-757.

2. Campbell, James B., and Randolph H. Wynne. (2011). Introduction to remote sensing. Guilford Press:

3. Das, Anup Kumar, C. P. Singh, Shiv Mohan, and A. Ajai. (2006). Polarization signatures of land cover classes using L-band polarimetric SAR data In Microwave Remote Sensing of the Atmosphere and Environment V, 6410: 641003:1-12

4. Dini Das, A. S., Shashi Kumar, Arun Babu, and Praveen K. Thakur. (2018). Insar coherence and polarimetric parameters based characterization of flooded area-case study of a natural world heritage site kaziranga national park. ISPRS Annals of Photogrammetry, Remote Sensing \& Spatial Information SciencesIV-5: 265-272

5. Dos Santos, J., I. Narvaes, P. M. L. A. Graça, and F. Goncalves. (2009). Polarimetric responses and scattering mechanisms of tropical forest in the Brazilian Amazon. Advances in Geoscience and Remote Sensing: 183-206.

6. Freeman, Anthony, and Stephen L. Durden. (1998). A three-component scattering model for polarimetric SAR data. IEEE Transactions on Geoscience and Remote Sensing 36.3: 963-973

7. Jat, Mahesh Kumar, P. K_ Garg, and Deepak Khare. (2008). Monitoring and modelling of urban sprawl using remote sensing and GIS techniques. International journal of Applied earth Observation and Geoinformation 10, 1: 26-43

8. Pampaloni, Paolo, and Kamal Sarabandi. (2004). Microwave remote sensing of land. URSI Radio Science Bulletin.308: 30-48.

9. Roy, P. S., Behera, M. D., \& Srivastav, S. K. (2017). Satellite remote sensing: sensors, applications and techniques, doi.org/10.1007/s40010-017-0428-8.

10.Sharma, J., R. Prasad, V. N. Mishra, V. P. Yadav, and R. Bala. (2018). Land Use and Land Cover Classification of Multispectral LANDSAT-8 Satellite Imagery Using Discrete Wavelet Transform. International Archives of the Photogrammetry, Remote Sensing and Spatial Information Sciences 42: 5,doi.org/10.5194/isprs-archives-XLII-5-703-2018.

11.Sim, C. K., K. Abdullah, MZ Mat Jafri, and H. S. Lim. (2011). Land Cover Classification of ALOS PALSAR Data Using Maximum Likelihood and Dual Mode Polarization.19 (S): 83-88.

12.Zakeri, Homa, Fumio Yamazaki, and Wen Liu. (2017). Texture analysis and land cover classification of Tehran using polarimetric synthetic aperture radar imagery. Applied Sciences 7.5: 452,2; doi.org/10.3390/app7050452. 